\title{
HYBRID AIR PURIFIER
}

\section{Kulvinder Singh}

Department of Physics, Deen Dayal Upadhyaya College, University of Delhi, Delhi, India

ABSTRACT

A hybrid air purifier with a simple design is fabricated and tested for air purification under indoor conditions. Experimental results show that along with the PM1, PM2.5, PM5, PM10, the particle of size $>0.3 \mu \mathrm{m}-10 \mu \mathrm{m}$, show a drastic decrease at the outlet of the air purifier when the purifier is switched on.

KEYWORDS : Air purification, nanotechnology, silver nanoparticles, and titanium dioxide.

\section{INTRODUCTION}

Air quality is an important concern for health all over the world. Primarily in developing countries like India, it becomes even more significant. Studies show that air quality is far below the safe levels in most metropolitan cities in India especially its capital Delhi [1-4]. The present work is planned to keep Delhi pollution at the centre of the project. Studies reveal that the most prominent factors causing pollution in Delhi are particulate matter (PM), sulphur dioxide $\left(\mathrm{SO}_{2}\right)$ and nitrogen dioxide $\left(\mathrm{NO}_{2}\right)$. [1]. Most of the commercial air purifiers in India are using high-efficiency particulate absorbent (HEPA) filters along with activated charcoal filters. Such filters are good in removing bacteria, viruses, and volatile organic compounds but have limited effect in arresting these gas molecules. HEPA filter can arrest particulate matter having size $>0.3 \mu \mathrm{m}$. Whereas the size of such molecules is few tens of nano-meter. Sulphur dioxide has good solubility in water (11.28g in 100g of water at 293K) [5]. At the same time nitrogen dioxide hydrolysis in water [6] showing high solubility. Many particulate matter ions are soluble in water. Keep these properties in mind present design was fabricated and found to be effective.

\section{PRESENT DESIGN}

Present design includes the following step by step processes: 1. Prefiltering: It removes the dust particles, organic floating fibres from the air. For this, double layer and low-density Polyurethane foam sheet of thickness 2 inches is used. Low density helps in fast flow of air.

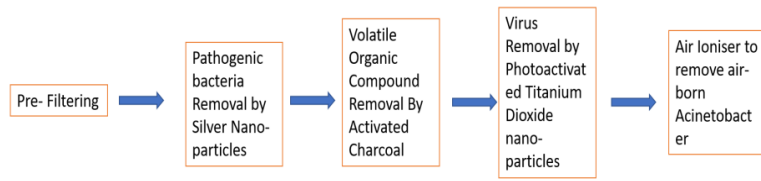

Fig.1 Step by step progression of the process

2. Pre-filtered air is sucked by the vacuum pump through $a 6$ $\mathrm{cm}$ diameter CPVC pipe. Air allowed to pass through the $20 \mathrm{~cm}$ water column. This gives sufficient time to dissolve $\mathrm{NO}_{2}$ and $\mathrm{SO}_{2}$ in water. Water is additionally added with silver nano-particles. Silver nano-particle in water known to have a property to kill pathogenic bacteria [7].

3. Air then is allowed to pass through activated charcoal lumps. This helps in the removal of volatile organic compounds.

4. Photoactivated titanium dioxide nanoparticles are known to be sanitizer [8]. For photoactivation, incandescent bulb with a fused-quartz filter is used to obtain Ultra-violet radiation $360-400 \mathrm{~nm}$.

5. Air Ioniser to remove air-born Acinetobacter is used just before exist of purified air.

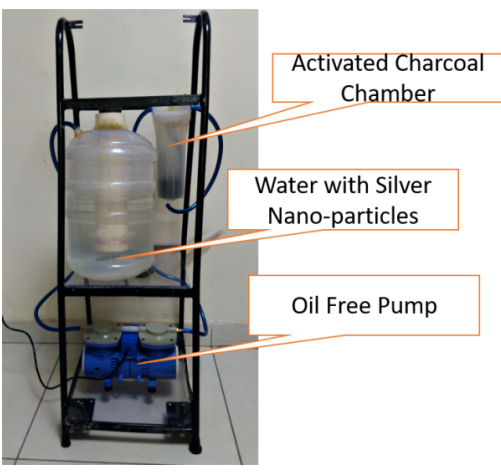

Fig. 2 Hybrid Air-purifier

\section{EXPERIMENTAL RESULTS AND DISCUSSIONS}

PM1, PM2.5, PM5, PM10, the particle of size $>0.3 \mu \mathrm{m},>1 \mu \mathrm{m}$ $>2.5 \mu \mathrm{m},>5 \mu \mathrm{m}$ and $>10 \mu \mathrm{m}$ were measured in real-time using Laser scattering based air quality tester. The air purifier was continuously switched on and off. In-situ, parameters were recorded. Fig 2 shows the variation of these parameters.

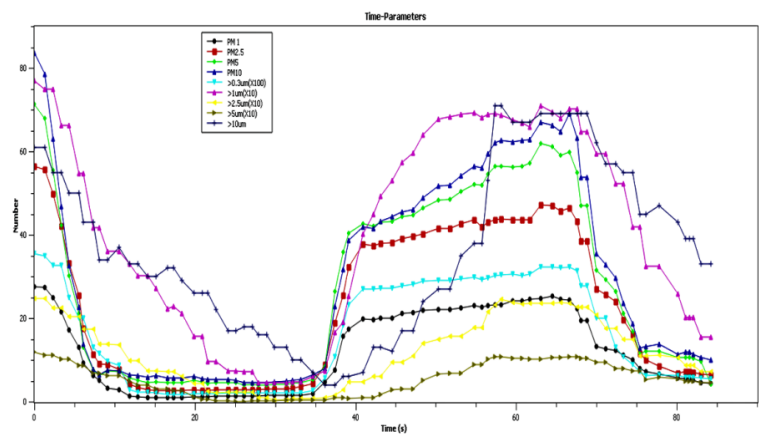

Fig.3. The PM and particle number variation in real-time.

The graph in Figure 3 clearly indicates the decrease of PMl, PM2.5, PM5, PM10, the particle of size $>0.3 \mu \mathrm{m},>2.5 \mu \mathrm{m}$ and $>5 \mu \mathrm{m}$ decreases when the purifier is switched on. Their number starts increasing as soon as air-purifier is switched off. Only Particle size $>1 \mu \mathrm{m}$ and $>10 \mu \mathrm{m}$ show delayed trend. This primarily is attributed to slow response time of detectors as trend is of repeated nature.

\section{CONCLUSION}

The present design is a simple design. It is quite effective for reduction of $\mathrm{SO}_{2}, \mathrm{NO}_{2}$ and particulate matter. As far as maintenance is concerned it requires change of water after running for 200 hour subject to moderate pollution. In case of high pollution, water can be changed after $100 \mathrm{hr}$ of running.

\section{ACKNOWLEDGEMENTS}

The author acknowledges the financial support provided by 
the Deen Dayal Upadhyaya College University of Delhi.

\section{REFERENCES}

[1] Ishita Jalan and Hem H. Dholakia "What is Polluting Delhi" -2019 Council on Energy, Environment and Water, https:// www. ceew. in/sites/default/files/CEEW_What_is_P olluting_Delhi_Air_Issue_Brief_PDF_ 12Apr 19. pdf

[2] Sourangsu Chowdhurya,b, Sagnik Deya,f, Larry Di Girolamoc, Kirk R Smithb,d , Ajay Pillarisettib , Alexei Lyapustine "Tracking ambient PM2.5 build-up in Delhi national capital region during the dry season over 15 years using a high-resolution ( $\mathrm{km}$ ) satellite aerosol dataset" Atmospheric Environment 204 (2019) 142-150

[3] "Air pollution in Delhi-An analysis" - 2016 http:// cpcbenvis. nic. in/envis_newsletter/Air\%20pollution\%20in\%20Delhi.pdf

[4] "Air quality bulletin" - January 2016, Air Lab, CPCB, available at http://www.cpcb.nic.in/AQI Bulletin Jan2016 AirLab.pdf.

[5] G.W.C. Kage and T.H. Laby "Table of Physical and Chemical Contents" 15th edition 1986 Longman NY p-219

[6] Sugata P Tan and Mohamamd Piri, "Modeling the solubility of Nitrogen dioxide in water uisng Perturbed-chain static Association Fluid Theory" Ind. Eng. Chem. Res. 2013,52,45,16032-16043, American Chemical Society.

[7] Mohammed TahaMoustafa "Removal of pathogenic bacteria from wastewater using silver nanoparticles synthesized by two fungal species" Water Science, Volume 31, Issue 2, October 2017, Pages 164-176

[8] Sujata Sirsat A and Jack Neal A "Titanium Dioxide Nanoparticles as an Environmental Sanitizing Agent" J Microb Biochem Technol 2015, 7:2 DOI: $10.4172 / 1948-5948.1000183$ 